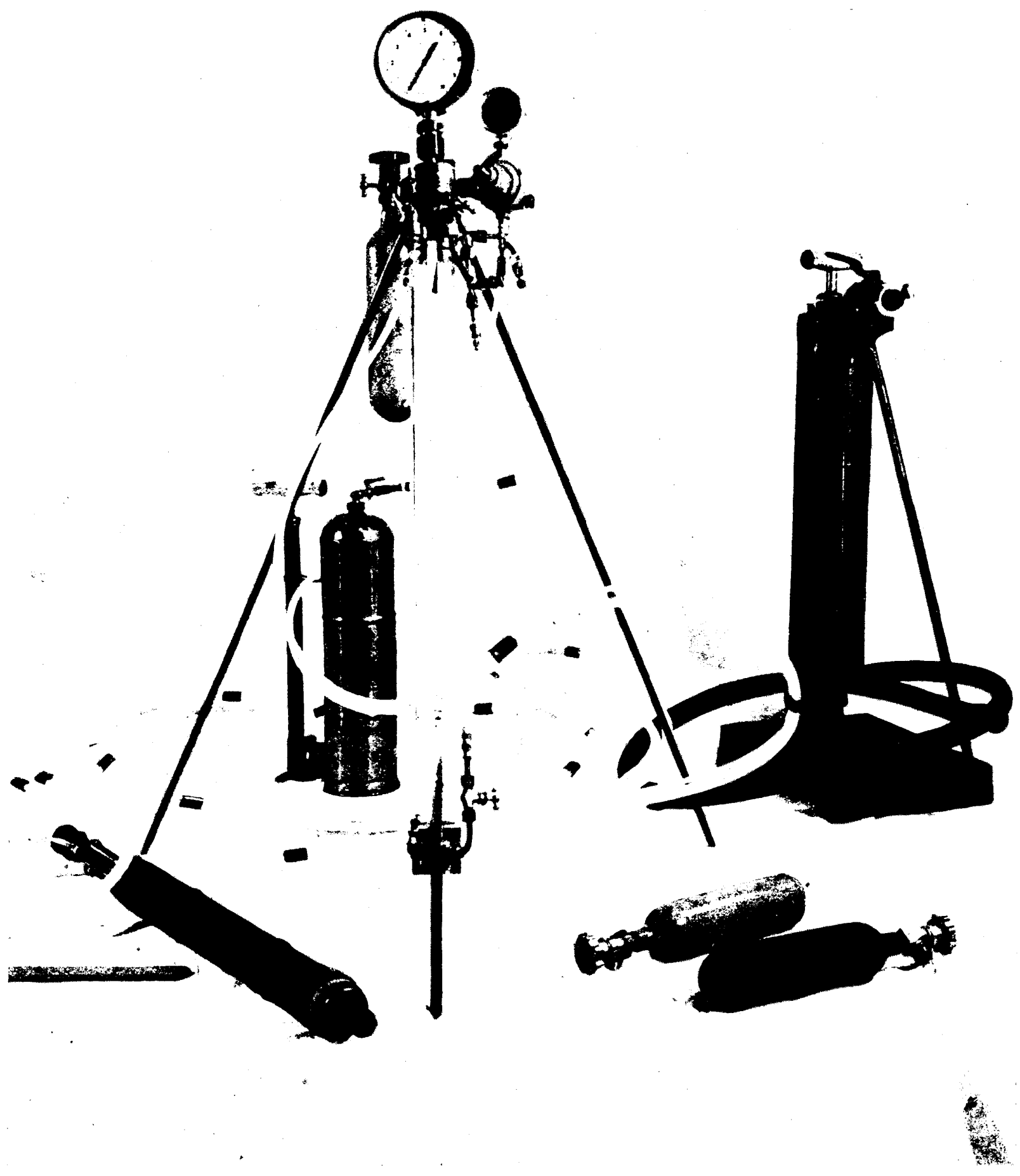

$478-3$

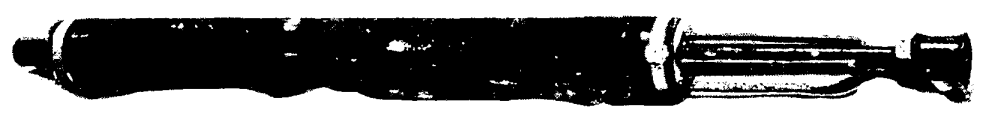

\title{
el presiómetro ménard
}


Dada la diversidad de suelos y sus distintas características, el cálculo real de la capacidad de sustentación, en cada caso particular, ha sido siempre un problema que ha requerido atención y análisis para pronunciarse en datos prácticos aplicables a la determinación de superficies necesarias con losas y apoyos de elementos sobre los que carga la obra muerta de la superestructura.

El "presiómetro" Ménard viene a contribuir en este problema de mecánica del suelo como ayuda práctica en la apreciación rápida y próxima a la realidad del coeficiente de carga admisible en cada terreno, de acuerdo con el análisis de las curvas de variación de volumen que se pueden obtener utilizando este aparato.

El método seguido en este procedimiento consiste en la introducción en el suelo de una sonda especial, cuyas paredes se someten a un juego de presiones que permiten conocer las reacciones que provoca el suelo sobre las paredes de esta sonda especial.

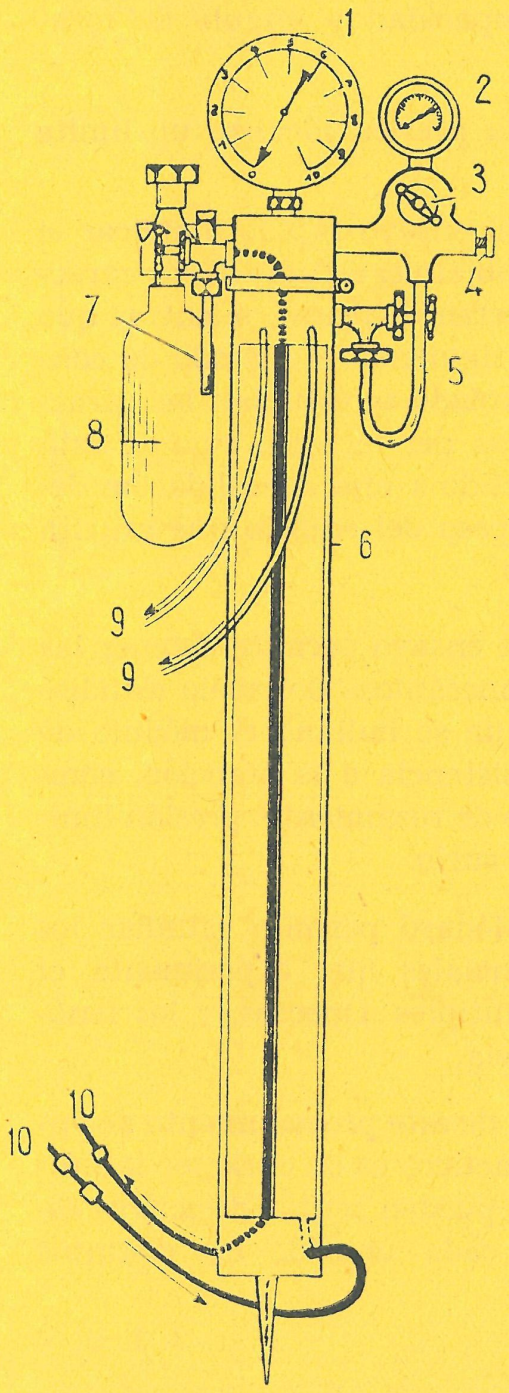

\section{Sonda}

1. Toma de gas. -2. Toma de agu: 3. Varilla de ajuste. - 4. Célula supe rior. -5 . Célula dilatable de medida.
6 . Cerferior.

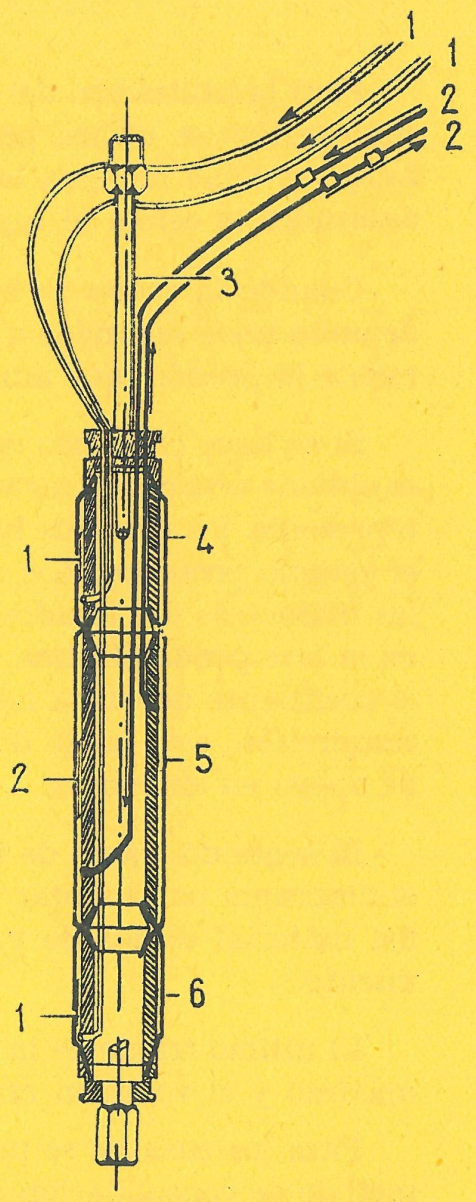

El aparato consta, esencialmente, en una sonda y un cilindro que controla las variaciones de volumen. La sonda se ha subdividido en tres células de membranas de caucho, cuya dilatación se realiza por medio de la inyección de agua a presión controlada con un manómetro. Estas células se han formado de tal manera, que sólo permitan una expansión radial. La célula central regula las observaciones, mientras que la inferior y superior tienen por objeto eliminar todas aquellas causas que impedirían una repartición cilíndrica de las deformaciones objeto de estudio y observación.

El cilindro que controla el volumen es de cristal, graduado, y permite leer las variaciones de volumen debidas a la dilatación de la célula central. La inyección de agua en las células se verifica por medio de gas a presión retenido en un depósito que se halla en la parte superior del cilindro. Este gas, conducido por canalizaciones especiales, actúa sobre las dos células que comprenden a la central.

\section{Confrolador de volumen}

1. Manómetro de medida.-2. Manómetro para el gas.-3. Reductor de presión. 8. Botella de gas comprimido. - 9 . Circulación de gas.-10. Circulación de agua. 
Para la utilización del aparato se empieza abriendo un taladro de unos $65 \mathrm{~mm}$ de diámetro, cuyo testigo se utiliza para estudiar la constitución y características del suelo en estudio. Luego se llena de agua la célula y el cilindro que regula la presión, procediendo después a descender la célula al lugar donde ha de estudiarse el terreno.

Cuando la sonda se halla en posición se van aumentando las presiones progresivamente, dejando unos segundos o minutos de tiempo a presión constante antes de aumentar nueva- mente la presión, que aumenta por saltos de 250 a 500 g, según los casos.

Si se hace el gráfico de las variaciones de volumen de la célula en función de las presiones, se obtiene una curva característica cuya rama se divide en cuatro partes, de la que la primera representa los cambios hasta llegar al equilibrio, por lo que no se tiene en consideración en el estudio posterior. Los otros tres tramos presentan, el primero, una proporcionalidad entre los diámetros del taladro y la presión aplicada, es decir, es una recta. Esta zona se halla en la fase pendo-plástica, y la pendiente de la curva representa la compresión del suelo. Como el coeficiente de carga admisible en un suelo es frecuentemente proporcional al módulo de compresión, esta parte del diagrama tiene gran importancia en el cálculo de zapatas y losas de apoyo en cimientos.

El segundo tramo de interés corresponde a las rupturas o desgarres, y se caracteriza en el diagrama por adoptar una forma exponencial. Esta zona permite trazar la curva intrínseca del material estudiado y, por tanto, el conocimiento de la compacidad y ángulo de rozamiento.

El último tramo de la curva presenta una forma asintótica, la presión alcanza un límite máximo y el volumen crece considerablemente.

Para los ensayos se pueden seguir dos caminos diferentes: un ensayo rápido o aplicar el método de consolidación controlada. El ensayo rápido tiene por objeto el estudio de las características del terreno natural, mientras que en los ensayos siguiendo el método de consolidación controlada se estudian las carac-

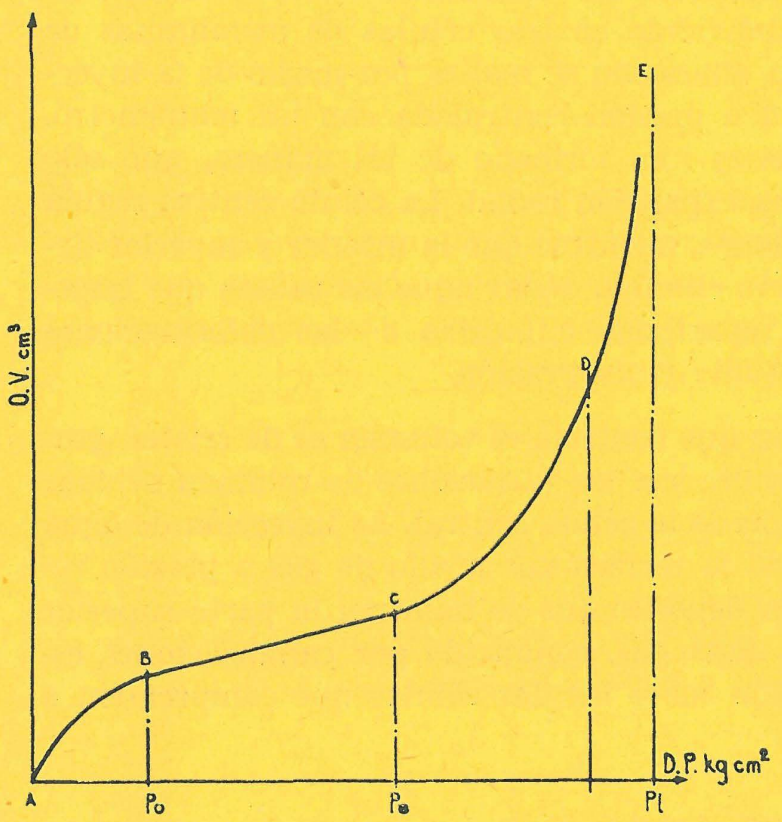

Diagrama teórico de presiones y deformaciones terísticas futuras del terreno, cuando está cargado y sometido a una consolidación debida al propio peso del edificio que gravita sobre el terreno.

Cada método de ensayo permite obtener las características mecánicas del suelo estudiado; entre las que se hallan: el módulo de compresión, resistencia a la tracción, compacidad, ángulo de rozamiento, presión límite y rigidez del suelo.

El aparato Ménard permite estudiar los asientos diferenciales que experimenta el suelo en sus mútiples aspectos, y los fenómenos de fluencia.

La aplicación de este procedimiento de ensayo a casos prácticos es de carácter tan diverso que no se pueden sentar directivas específicas para cada uno de los distintos casos.

J. J. U. 